\title{
Low Occupancy Rates of Artificial Nest Cavities by European Starlings
}

THOMAS W. SEAMANS, BRADLEY F. BLACKWELL ${ }^{1}$ AND LAURA A.TYSON, USDA, Wildlife Services, National Wildlife Research Center, Sandusky, OH, USA

ABSTRACT. European Starlings (Sturnus vulgaris) are known for their generalist ecological requirements and compete for available cavity nest sites with native species. Our purpose was to revisit recent findings with regard to starling selection of artificial nest structures. In previous studies involving starling use of wooden nest boxes in northern Ohio, starling occupancy across sites ranged from 67 to 100 percent; use by native species was minimal. In this study, we made available 25 wooden boxes and 25 PVC nest tubes for starling nesting, but we were forced to forego planned treatments because of low starling occupancy rates. We found a maximum occupancy rate of $\mathbf{4 0}$ percent for starlings, whereas Eastern Bluebirds (Sialia sialis) and Tree Swallows (Tachycineta bicolor) had a combined minimal occupancy rate of 52 percent. We speculate that an increase in availability of dead ash trees (Fraxinus spp.) due to damage by the emerald ash borer (Agrilus planipennis), as well as a potential increase in natural cavities due to an increasing Red-bellied Woodpecker (Melanerpes carolinus) population might explain our findings. With potentially fewer starlings selecting artificial structures native species might now exploit these artificial nest sites.

\section{INTRODUCTION}

The European Starling (Sturnus vulgaris) has been considered a competitive threat to cavity-nesting birds in the United States, as well as a pest species and hazard to aviation safety (Feare 1984; Ingold 1994; Dolbeer et al. 2013). The success of the Starling is considered to be a consequence of its generalist ecological requirements (Kessell 1957) and its ability to live near and benefit from humans (Crick et al. 2002). Further, Starlings make use of a variety of nest sites (Kessell 1957; Feare 1984). In studies conducted in northern Ohio from 1988 through 2006 Starlings occupied 67 to 100 percent of artificial nest boxes, whereas native species use was minimal (2.5 to 28.0 percent) (Dolbeer et al. 1988; Belant et al. 1998; Seamans et al. 2001; White and Blackwell 2003; Seamans and Helon 2006). However, Tyson et al. (2011) found that when polyvinyl chloride (PVC) nest tubes $(9.5-\mathrm{cm}$ inside diameter x $27.5-\mathrm{cm}$ long) were placed in the same area they were not used by starlings, but the reasons why remain unclear. Tyson et al. (2011) speculated that vertical depth of the PVC tubes might have been a limiting factor for starlings. However, the PVC tubes were used by Tree Swallows (Tachycineta bicolor) and Eastern Bluebirds (Sialia sialis).

Address correspondence to Bradley F. Blackwell, USDA Wildlife Services, National Wildlife Research Center, Sandusky, OH 44870. Email: bradley.f.blackwell@APHIS.USDA.gov
Our purpose was to revisit the findings by Tyson et al. (2011) in the context of quantifying the effects of cavity type (wooden nest box versus a PVC tube with $>9.5$-cm vertical depth) and a commercially marketed nesting deterrent in a factorial design. However, low occupancy rates of wooden nest boxes and larger PVC nest tubes by starlings forced us to forego treatments. Instead, we report our observations on nest occupancy by starlings and speculate as to potential reasons for these unanticipated nesting rates.

\section{METHODS}

We conducted our study on the 2,200-ha National Aeronautic and Space Administration Plum Brook Station (PBS), Erie County, Ohio during spring/ summer 2013 (see Tyson et al. 2011 for study area description). In prior studies completed at PBS, nest boxes were attached to 50 to 100 utility poles (Dolbeer et al. 1988; Belant et al. 1998; Seamans et al. 2001; White and Blackwell 2003; Seamans and Helon 2006). For our intended experiment we attached 25 wooden nest boxes ( $28 \times 13 \times 17 \mathrm{~cm} ; 5.1$ - cm diameter entrance) to utility poles 2.5 to $3.0 \mathrm{~m}$ above the ground and with an aluminum predator guard below the box; each box was at least $240 \mathrm{~m}$ from the nearest box. In addition, we attached 25 PVC nest tubes (15.0-cm diameter $\mathrm{x}$ 28-cm long with 5.1-cm diameter entrance) in the same manner. Utility poles on PBS are in grass margins (20 to 30-m wide) along roadways and bordering either wooded areas or agricultural fields. We installed 25 
PVC nest tubes in March 2012, and these remained open, but not monitored until spring 2013. During March 2013 we checked all PVC nest tubes, removed remnant nest material and closed the entrance hole until 15 April 2013. The 25 wooden next boxes were installed in March 2013, but not opened until 15 April 2013. Nest checks were then conducted twice per week from 18 April to 3 June 2013.

\section{RESULTS}

Twenty-three of 25 nest boxes and all 25 nest tubes were occupied. Starlings nested in 40 percent of boxes and 24 percent of tubes, whereas Eastern Bluebirds and Tree Swallows combined nested in 52 percent of boxes and 76 percent of tubes. Overall, starlings initiated nesting (29 April \pm four days) before Eastern Bluebirds (6 May \pm five days) and Tree Swallows (12 May \pm six days). Starlings completed 100 percent of clutches in both boxes and tubes. One bluebird nest in a box failed while Tree Swallows nests failed in three boxes and four tubes.

\section{DISCUSSION}

Despite a combined occupancy rate of 96 percent for all nest structures, starling use was notably lower, while native species use was higher than in previous PBS studies (Dolbeer et al. 1988; Belant et al. 1998; Seamans et al. 2001; White and Blackwell 2003; Seamans and Helon 2006). We note that the PVC nest tubes used in this study were approximately one year old, and the design and materials for the wooden next boxes were the same as for boxes used in the aforementioned studies. Further, as indicated above, the tubes were 1.6 times larger than those used by Tyson et al. (2011) and were used by starlings in this study. However, according to Kessel (1957) starlings tend to choose nest sites close to ones they used the previous year, and birds will monitor candidate cavity sites through late summer and fall. During our study, the wooden nest boxes were made available for a full nesting season only in 2013. Therefore, nest site age relative to previous use by starlings (Kessel 1957) might explain the lower occupancy. However, in a previous study, starlings occupied 84 percent of nest boxes placed in March and opened in April (Belant et al. 1998). Thus, the difference in occupancy rates between starlings and native species for both cavity types begs the question as to availability of more desirable cavity sources or declines in population levels.

Koenig et al. (2013) found that Red-bellied
Woodpecker (Melanerpes carolinus) populations increased in areas of Emerald Ash Borer (Agrilus planipennis) invasion. Both emerald ash borer, first discovered in Ohio in 2003 (ODNR 2015) and Redbellied Woodpeckers are present on PBS. In a study in Ohio, Ingold (1994) found that starlings usurped 39 percent of Red-bellied Woodpecker cavities, 14 percent of Northern Flicker (Colaptes auratus) cavities and 15 percent of Red-headed Woodpecker (Melanerpes erythrocephalus) cavities. However, at least 59 percent of the pairs of usurped birds excavated a second cavity or reclaimed an older cavity. Assuming that a similar pattern of increased cavity excavation is occurring in our area, there is likely an increasing number of natural cavities for starling use. Additionally, Ingold (1998) found that starlings preferred Northern Flicker excavated cavities even when Northern Flicker nest boxes were available. If this tendency of favoring natural cavities is accurate, even when nest boxes designed for starlings are present, the lower occupancy rates of nest boxes in our current work could be the result of increased woodpecker activity and thus increased availability of cavities.

In addition, from 2001 to 2011 starling populations have exhibited a slight decline of 1.6 percent per year in the Lower Great Lakes and Saint Lawrence Plain area (Sauer et al. 2012). Still, we contend that these declines are not enough to reasonably consider artificial nest cavities as superfluous for starlings. In other words, it is reasonable to conclude that more desirable natural cavities are available. Further, the increase in use of artificial nest cavities by native species occurred despite slight declines within the Lower Great Lakes and Saint Lawrence Plains for both Tree Swallows (-2.8 percent) and bluebirds ( -0.5 percent; Sauer et al. 2012). In addition, Rendell and Robertson (1990) found that Tree Swallows preferred nest boxes located away from the forest edge to avoid interactions with competitors for nest sites. Therefore, we suggest that the decline in starling use of artificial nest cavities has allowed native species to successfully exploit the artificial cavities for nesting. We suggest that future research efforts consider the question of natural cavity site availability by comparing cavity use by indigenous species and starlings in a block design comprising natural and artificial cavity sites.

\section{ACKNOWLEDGMENTS}

Our study was funded by the U.S. Department of Agriculture, Animal and Plant Health Inspection 
Service, Wildlife Services, National Wildlife Research Center. We thank J. Jones for field assistance. We thank T. DeVault and B. Washburn for reviews of the manuscript.

\section{LITERATURE CITED}

Belant JL, Woronecki PP, Dolbeer RA, Seamans TW. 1998. Ineffectiveness of five commercial deterrents for nesting starlings. Wildl Soc Bull 26 (2): 264-268.

Crick HQP, Robinson RA, Appleton GF, Clark NA, Rickard AD (editors). 2002. Investigation into the causes of the decline of starlings and house sparrows in Great Britain. BTO Research Report 290. Defra, London.

Dolbeer RA, Link MA, Woronecki PP. 1988. Naphthalene shows no repellency for starlings. Wildl Soc Bull 16 (1): 62-64.

Dolbeer RA, Wright SE, Weller J, Begier MJ. 2013. Wildlife strikes to civil aircraft in the United States, 1990-2012. U.S. Department of Transportation, Federal Aviation Administration, Office of Airport Safety and Standards, Serial Report 19, Washington, D.C., USA.

Feare C. 1984. The Starling. New York (NY): Oxford University Press.

Ingold D. 1994. Influence of nest-site competition between European Starlings and woodpeckers. Wilson Bull 106 (2): 227-241.

Ingold D. 1998. The influence of starlings on flicker reproduction when both naturally excavated cavities and artificial nest boxes are available. Wilson Bull 110 (2): 218-225.
Kessel B. 1957. A study of the breeding biology of the European Starling (Sturnus vulgaris L.) in North America. Amer Midl Nat 58 (2): 257-331.

Koenig WD, Liebhold AM, Bonter DN, Hochachka WM, Dickinson JL. 2013. Effects of the emerald ash borer invasion on four species of birds. Biol Invasions 15 (9): 2095-2103. dOI 10.1007/s10530-013-0435-x.

Ohio Department of Natural Resources. Insects and Diseases; [accessed 2015 October 12]. http://forestry.ohiodnr.gov/pests

Rendell WB, Robertson RJ. 1990. Influence of forest edge on nest-site selection by tree swallows. Wilson Bull 102 (4): 634-644.

Sauer JR, Hines JE, Fallon JE, Pardieck KL, Ziolkowski DJ, Jr, Link WA. 2012. The North American breeding bird survey, results and analysis 1966 - 2011. Version 07.03.2013 Laurel, MD: USGS Patuxent Wildlife Research Center [accessed 2015 September 1]. http://www.mbr-pwrc.usgs.gov/bbs/

Seamans TW, Lovell CD, Dolbeer RA, Cepek JD. 2001. Evaluation of mirrors to deter nesting starlings. Wildl Soc Bull 29 (4): 1061-1066.

Seamans TW, Helon DA. 2006. Evaluation of the Chromaflair crow buster as a starling repellent at nest sites. Proc Vert Pest Conf 22 (4): 228-230.

Tyson LA, Blackwell BF, Seamans TW. 2011. Artificial nest cavity used successfully by native species and avoided by European Starlings. Wilson J Ornithol 123 (4): 827-830.

White RJ, Blackwell BF. 2003. Ineffectiveness of sulfur-based odors as nesting deterrents against European Starlings. Ohio J Sci 103 (5): 126-128. 